\title{
The longitudinal effects of midwife-led postnatal debriefing on the psychological health of mothers
}

\author{
Rosemary SELKirk, SuZANNe McLaren, \\ Alison Ollerenshaw \& Angus J. McLachlan \\ University of Ballarat, Australia
}

JULIE MOTEN

Ballarat Health Services, Australia

\begin{abstract}
To assess the effect of midwife-led postpartum debriefing on psychological variables, 149 women were recruited in the third trimester of their pregnancy and were randomly assigned to treatment and control conditions. Women in the treatment group received midwife-led postpartum debriefing within 3 days postpartum, whereas women in the control group did not receive formalised debriefing. Background information and psychological variables were assessed in the prepartum, and birthing information was gathered 2 days postpartum. The psychological variables, plus a measure of birth trauma, were re-assessed at 1 month, and again, together with a measure of parenting stress, at 3 months postpartum. Although the majority of women reported positively on their debriefing experience, statistical analyses indicated that only on the measure of dyadic satisfaction was there some suggestion that debriefing was effective. There were no significant differences between the treatment and control groups on measures of personal information, depression, anxiety, trauma, perception of the birth, or parenting stress at any assessment points, postpartum. On the other hand, the effect of medical intervention on women's perceptions of their birthing was evident, with women who experienced more medical intervention reporting more negative perceptions of their birthing than women who had experienced less medical intervention. Surprisingly, this difference was more marked among the women who had been debriefed than among the control group. Generally, the results did not support midwife-led debriefing as an effective intervention postpartum.
\end{abstract}

Significant life events and experiences that are generally regarded positively may also be a potential source of psychological stress and distress through the life span (Raphael \& Prague, 1996). In particular, there appears to be a potential risk of psychological

Address for correspondence: Dr Suzanne McLaren, School of Behavioural \& Social Sciences \& Humanities, University of Ballarat, University Drive, Mt Helen, Vic 3353, Australia. Tel: +61 35327 9628; Fax: +61 35327 9840; Email: s.mclaren@ballarat.edu.au 
damage for women following childbirth (Raphael-Leff, 1991; Simkin, 1991), despite childbirth being generally perceived as a major and positive life event (Boyce \& Condon, 2000). Empirical evidence indicates that some women's memories and perceptions of childbirth have been associated with significant adverse psychological effects, including lack of birth satisfaction (Green, 1993), negative birth perceptions (Cranley et al., 1983), and deterioration in mood and self-esteem (Fisher et al., 1997). There is also evidence that assisted delivery (Astbury et al., 1994) and difficult childbirth (Bergant et al., 1999) are associated with postnatal depressive symptoms.

Postnatal depression (PND) refers to a range of depressive symptoms of varying severity and prolongation that may be experienced by the mother up to 2 months after childbirth and persist for a year or longer (Albright, 1993). Women suffering from PND have been found to experience elevated levels of anxiety (Green, 1998), reduced levels of satisfaction with partner, and lack of enjoyment and positive attitude towards the infant (Webster et al., 1994). Current indicators suggest the incidence of PND ranges between 3 and 27\% (Milgrom \& McCloud, 1996), depending upon the measures employed to study the population characteristics. Various factors associated with childbirth have been linked with the development of PND. Biological (Harris, 1994), medical/obstetric (Burger et al., 1993), and psychiatric and psychological (McMahon et al., 2001) factors have been implicated in the condition, as well as specific aspects of personal history (sexual abuse; Rhodes \& Hutchinson, 1994) and psychosocial characteristics (dyadic satisfaction; Webster et al., 1994).

Post traumatic stress disorder (PTSD) is another psychological disorder that may occur after childbirth. PTSD may have a smaller incidence rate, but can be as disruptive as PND. Two British studies suggest that between 5 and $10 \%$ of women may experience a high level of distress 1 month after delivery, with a similar percentage experiencing a medium level of PTSD type distress at this time (Allen, 1999; Lyons, 1998).

The evolution of midwife-led postnatal debriefing, as a tool for assisting women after childbirth, has grown from its uncritical acceptance as a useful psychological technique to its considered use as one possible adjunct during post-natal care. Originally developed as a group process for emergency personnel after exposure to a critical incident or disaster, psychological debriefing has been transferred to the individual context. The main aim of psychological debriefing is to prevent the development of permanent emotional injury, by enabling normalising cognitive appraisal and emotional processing of the traumatic experience (Kaplan et al., 2001). Debriefing provides the opportunity to acknowledge grief, vent emotion, and construct a coherent whole of the experiences. The process appears to be beneficial in increasing morale and self-esteem (Rose, 1997).

Postnatal debriefing has been defined in different ways. Authors such as Ball (1988), for example, suggested that providing women with the opportunity to integrate their birth experience through education about that experience might be beneficial in strengthening psychological processes. Raphael-Leff (1991) proposed that reexamining the birth would help women evaluate and integrate this extraordinary event into their particular everyday life experience. For the purposes of this study, postnatal debriefing refers to a midwife-led, semi-structured interview with the mother around 3 days postpartum.

Anecdotal evidence abounds that postnatal debriefing is valued by those who choose it (Charles \& Curtis, 1994; Smith \& Mitchell, 1996; Westley, 1997). Early evidence 
suggested it may be a valid method of reducing psychological morbidity (Snaith \& Zigmond, 1994), however, the current empirical evidence relating to the efficacy of debriefing is conflicting. A study by Lavinder and Walkinshaw (1998) provides support for the proposal that postnatal debriefing is associated with positive psychological outcomes. In this study, debriefing comprised a 30-120-minute interactive, midwifeled interview whereby women spent as much time as needed discussing their labour, asking questions and exploring their feelings. They found that women who received debriefing were less likely to have elevated anxiety and depression 3 weeks postnatally than those mothers who did not receive debriefing.

These findings contrast with the research of Henderson et al. (1998), who found no significant differences in levels of depression at 2, 6, and 12 months postpartum between those women who received midwife-led debriefing and those who did not. In this study, debriefing consisted of a single structured stress debriefing conducted by a trained midwife. Similarly, a study by Small et al. (2000) found no differences in depression following midwife-led debriefing for women who experienced operative childbirth. In this study, the debriefing intervention, which lasted up to 1 hour in duration, provided women with an opportunity to discuss their birthing with a midwife who was experienced in talking with women about their birth, was an emphatic listener and was knowledgeable about the common concerns and issues of women who had experienced operative deliveries. The content of the debriefing session was determined by the woman's own experiences and concerns (Small et al., 2000). More recently, Priest et al. (2003) found no significant differences on post traumatic stress and depression between those women who received debriefing and those who did not, when they were assessed at 2,6 , and 12 months postpartum. This study was also unable to detect any major differences in the proportion of women who were diagnosed with stress disorder or with major or minor depressions at 1-year postpartum. The debriefing intervention comprised a single, standard debriefing session led by trained midwives and based upon a seven stage critical incident stress debriefing model which had been adapted for use in postpartum debriefing sessions. Each debriefing session lasted between 15 minutes and 1 hour in duration.

Several reasons exist for the apparent inconsistencies in the findings: failure to control for variability in prepartum conditions, variability in the birth and postpartum experience; and employment of differing postpartum measures. The present study controls for variables that have been identified in previous research as confounding variables, including antenatal psychological health, levels of depression and anxiety, and dyadic adjustment. To our knowledge, this is the first study of its kind to investigate trauma, anxiety and depression simultaneously; to add measures of dyadic adjustment and parenting stress; and to control for a wider range of psychological variables both pre- and postpartum.

\section{Method}

\section{Participants}

Participants were recruited to the study from a large regional hospital in Victoria, Australia, over a 3-month period between January and April 2001. Ethics approval was granted from the hospital and tertiary institution from which the study was being conducted. Initially, 180 women were approached to participate in the study. In total, 149 women $(83 \%)$ agreed to participate and were recruited to the study in the third 
trimester ( $\geqslant 28$ weeks) of their pregnancy. At this time, participants were randomly allocated to treatment and control groups, in order of the receipt of their completed informed consent forms. Each participant's completed consent form was numbered as it arrived. Those participants with an odd number were allocated to the treatment group, and those participants with an even number were allocated to the control group. A sticker was placed on the medical file of each participant alerting midwifery staff of mothers who were to be debriefed before discharge from the hospital.

\section{Measures}

Background Information Questionnaire. A 27-item questionnaire was designed by the researchers to gain information about the birth and parenting expectations, previous psychological history (depression and anxiety), and demographic details.

Symptom Checklist 90-R (SCL 90-R). Designed by Derogatis (1994), the SCL-90-R is a measure of psychological symptomology. The 90 -item self-report inventory is rated on a five-point scale of distress ( $0=$ 'not at all'; $4=$ 'extremely'). The SCL-90-R yields nine primary symptom dimensions: (1) Somatisation; (2) Obsessive-Compulsion; (3) Interpersonal Sensitivity, (4) Depression, (5) Anxiety, (6) Hostility, (7) Phobic Anxiety, (8) Paranoid Ideation, and (9) Psychoticism. In addition, a single summary score, the Global Severity Index, indicates the current level or depth of disorder.

Internal reliability coefficients range from $\alpha=0.77$ to $\alpha=0.90$ for the nine primary symptoms and test-retest reliability at 10 weeks for these symptoms range from $\alpha=0.68$ to $\alpha=0.83$. The SCL- $90-\mathrm{R}$ has been used as a measurement of change in clinical cohorts and as outcome measures of psychotherapeutic, psychopharmacology and other treatment research (Derogatis, 1994). In this study the Cronbach $\alpha$ coefficient ranged from $\alpha=0.73$ to $\alpha=0.87$ for the nine primary symptoms.

Dyadic Adjustment Scale (DAS). The DAS is a 32-item self report questionnaire developed by Spanier (1989) to measure dyadic relationship or adult partnership quality. Items are rated on a six-point scale ( $0=$ ' always disagree'; $5=$ 'always agree'), with higher scores indicating a better relationship.

Strong internal reliability has been reported, with the total score for dyadic adjustment being $\alpha=0.96$, and the subscales ranging from $\alpha=0.73$ to $\alpha=0.94$ (Spanier, 1989). The scale has been shown to have good criterion-related validity when comparing divorced and married groups of people (Spanier, 1989). In the present study the Cronbach $\alpha$ coefficient for dyadic adjustment was also strong, $\alpha=0.93$, with the subscales ranging from $\alpha=0.66$ to $\alpha=0.91$, and a median of $\alpha=0.81$.

State-Trait Anxiety Inventory (STAI). Spielberger (1983) designed the STAI as a twodimensional measure of trait and state anxiety. The STAI comprises 40 -items, with the first 20 items measuring state anxiety and items 21-40 measuring trait anxiety. Items are rated on a four-point scale ( $1=$ 'not at all'; 4 'very much so'), with higher scores indicating higher levels of anxiety.

Vines and Williams-Burgess (1994) reported strong internal reliability $(\alpha=0.88)$ in a study of mothers at high or low risk for child abuse using the STAI. Mercer and Ferketich (1990) reported strong internal reliability coefficients, ranging from $\alpha=0.92$ to $\alpha=0.95$ for state anxiety, and from $\alpha=0.90$ to $\alpha=0.93$ for trait anxiety, when using 
the STAI as part of a battery of tests seeking predictors of parental attachment. In the current study the Cronbach $\alpha$ coefficient was also strong, $\alpha=0.93$ for state anxiety and $\alpha=0.94$ for trait anxiety.

Edinburgh Postnatal Depression Scale (EPDS). Developed by Cox et al. (1997), the EPDS is a 10-item self-report measure of postnatal depressive symptoms, scored on a four-point rating scale ( $0=$ 'as much as I ever did'; $3=$ 'not at all'). Higher scores on the EPDS represent greater levels of depression.

The validity of the EPDS is generally reported in terms of sensitivity (the percentage of true depressed cases identified), specificity (the percentage of true non-depressed cases identified), and positive predictive value (the percentage of all cases positively identified as depressed correctly identified as such). Cox et al. (1987) reported EPDS sensitivity of $86 \%$, specificity of $78 \%$ and positive predictive value of $73 \%$.

Strong validity for the scale has been reported worldwide, with sensitivity and specificity rates ranging from $67.7 \%$ (Murray \& Carothers, 1990) to 100\% (Boyce et al., 1993). The scale has also been validated for use with non-postnatal women, yielding satisfactory sensitivity (79\%) and specificity (85\%) (Cox et al., 1996). Boyce et al. (1993) validated the EPDS for an Australian sample of 103 postpartum women, using the Diagnostic Interview Schedule. They reported EPDS sensitivity of $100 \%$, specificity of $95.7 \%$ and positive predictive value of $69.2 \%$ for this sample. In this study the Cronbach $\alpha$ coefficient was $\alpha=0.87$.

Perception of Birth Scale (POBS). Marut and Mercer (1979) designed this 29-item questionnaire to measure maternal perceptions of the labour and delivery experience. The women used a five-point rating scale ( $1=$ 'not at all'; $5=$ 'extremely') with higher scores indicative of fewer problems and a more positive perception of the birth experience.

Internal reliability coefficients of the instrument have been reported at $\alpha=0.83$ for 50 cases (Marut \& Mercer, 1979), and $\alpha=0.86$ for 360 cases (Fawcett et al., 1992). Fawcett and Knauth (1996) conducted an exploratory factor analysis of the scale which demonstrated strong reliability of $\alpha=0.85$ for a 25 -item version of the questionnaire with 320 women. In this study the Conbach $\alpha$ coefficient was also strong at $\alpha=0.86$.

Intrapartum Intervention Scale (IIS). The IIS was developed by Clement et al. (1999) and consists of 20 -items (yes/no responses) relating to medical procedures associated with the labour and delivery. IIS scores were only collected at Assessment point 2 (2 days postpartum). Two levels of this scale were used in the analysis, low and high levels of intervention, based on a median split of the sample. Participants scoring 28 or less were defined as having less medical intervention (low intervention), and those scoring more than 29 were defined as having more medical intervention (high intervention).

Impact of Events Scale (IES). Designed by Horowitz et al. (1979), the IES comprises 15 items requiring participants to respond to statements about stressful life events using a rating scale ranging from 0 to 5 ( $0=$ 'not at all'; $5=$ 'often'). High scores on this measure signified that the event, in this case the birth, had a significant effect on the mother.

Lee et al. (1996) found mean scores on the Intrusion and Avoidance subscales of women following miscarriage to be similar to those reported by Horowitz et al. (1979) 
for a sample of people suffering with stress response syndromes. Horowitz et al. (1979) reported split-half reliability for the total score as $r=0.86$. Internal consistency of the subscales was high for Intrusion $(\alpha=0.78)$ and Avoidance $(\alpha=0.82)$. Test-retest reliability at 1 week was satisfactory for Intrusion $(r=0.89)$, Avoidance $(r=0.79)$, and for the total score $(r=0.87)$. Other research has confirmed the test's reliability (e.g., Turner \& Lee, 1998). In this study the Cronbach $\alpha$ coefficient was high for the subscales Intrusion $(\alpha=0.80)$ and Avoidance $(\alpha=0.82)$, and for the total IES score $(\alpha=0.88)$.

Parenting Stress Index Short Form (PSI). The PSI is 36-item questionnaire designed by Abidin (1995) to measure participants' responses to parenting by circling one of five response categories, ranging from 'strongly agree' to 'strongly disagree'. Again, a high score on this index was associated with higher levels of stress.

Abidin (1995) reports strong test-retest reliability at the 6-month interval and internal reliability coefficients for the PSI, with $\alpha=0.84$ (test-retest) and $\alpha=0.91$ (internal reliability) obtained for the Total Stress score. Test-retest reliability for the three subscales ranges from $\alpha=0.68$ (Parent-Child Dysfunctional Interaction) to $\alpha=0.85$ (Parental Distress). Similarly, strong internal reliability has also been demonstrated for the three subscales, ranging from $\alpha=0.80$ (Parent-Child Dysfunctional Interaction) to $\alpha=0.87$ (Parental Distress). Internal reliability was strong in this study with the Cronbach $\alpha$ coefficient for the PSI being $\alpha=0.94$ for the total score, and $\alpha=0.90$ for each of the three subscales.

Feedback after Debriefing Questionnaire (FAD). The 20-item FAD was designed by the researchers to gain information about the women's perceptions of, feelings about, reactions to, and satisfaction with, their postnatal debriefing. Using a five-point scale ( $0=$ 'not at all'; $4=$ 'extremely'), participants were asked to respond to such items as how important it was for women to have debriefing, how useful they found debriefing, and how intrusive they thought it was.

\section{Procedure}

The procedure for the study involved the collection of self-report questionnaires at four assessment points. The sequence effect of questionnaire presentation was controlled by using a Latin square design. At the first assessment point all participants completed the Background Information Questionnaire, SCL 90-R, the DAS, the STAI and the EPDS, between the 28th week of gestation and their delivery. At the second assessment point, a day or two after giving birth, all participants completed the POBS and the IIS. At the third assessment point, 1 month after giving birth, all participants completed the EPDS, STAI, POBS and the IES, and at the fourth and final assessment point, 3 months postpartum, all participants completed the EPDS, DAS, STAI, POBS, IES and the PSI. Participants in the treatment group, who had been debriefed in hospital, also received a FAD questionnaire.

On the second or third day after delivery, around the second assessment point, women in the treatment group received midwife-led postnatal debriefing of between 30 and 60 minutes duration. The hospital midwife specifically employed for debriefing and parenting craft conducted the debriefings in a separate, private room. The debriefing session was consistent with the participating hospital's protocols and 
followed the guidelines outlined in the hospital's debriefing workshop manual. Each debriefing session consisted of eight distinct phases, summarised as follows: Phase 1 "Introduction": The mother is told that debriefing is confidential, non-judgement and allows her access to her labour and delivery information. Phase 2 "Fact Phase": The mother is invited to summarise her birth experience. Phase 3: "Thoughts Phase": The mother is asked to describe her thoughts about her birthing. Phase 4 "Feelings Phase": The midwife enquires after the mother's feelings during labour, delivery, and now, including reactions to physical sensations and unexpected occurrences. Phase 5 "Symptoms Phase": The midwife asks the mother to describe her current experience. Phase 6 "Education Phase": The midwife explains to the mother that it is normal and natural to experience a variety of signs, symptoms, and emotional reactions to the birth experience. The midwife clarifies events and myths surrounding the birth, and shares information from the partagraph and delivery notes. Phase 7 "Re-entry phase": The midwife summarises the mother's overall emotional reactions and response to her birthing expectations. The mother is given the opportunity to convey comments to management regarding the service provided during her birth. Phase 8 "Final Phase": Closure and information. Any further questions the mother has are answered, and information is provided on support services available (if necessary).

\section{Results}

\section{Preliminary group comparisons: Prepartum and post delivery measures}

A series of chi-square analyses of demographic variables comparing the treatment and control groups at the commencement of the study confirmed that the randomisation process had been successful. The two groups were similar in regards to marital status $\left(\chi^{2}=1.27, P>0.05\right)$, educational level $\left(\chi^{2}=2.34, P>0.05\right)$, employment status $\left(\chi^{2}=0.88, P>0.05\right)$, expectations of returning to work $\left(\chi^{2}=0.50, P>0.05\right)$, and financial security $\left(\chi^{2}=0.57, P>0.05\right)$. The groups also did not differ with respect to previous pregnancy and obstetric factors (first pregnancy $\left(\chi^{2}=0.08, P>0.05\right)$, first birth $\left(\chi^{2}=0.21, P>0.05\right)$, normal pregnancy $\left(\chi^{2}=0.46, P>0.05\right)$, delivery type $\left(\chi^{2}=0.11\right.$, $P>0.05)$, birth plan $\left(\chi^{2}=1.50, P>0.05\right)$ ) perceived support factors (family $\left(\chi^{2}=0.01\right.$, $P>0.05)$, and friends $\left(\chi^{2}=1.80, P>0.05\right)$ ), and history of psychiatric illness (depression $\left(\chi^{2}=2.78, P>0.05\right)$, anxiety $\left.\left(\chi^{2}=0.46, P>0.05\right)\right)$. Two $t$-tests also revealed that both groups were of similar age (Treatment group, $\mathrm{M}=28.43, \mathrm{SD}=4.70$; Control group, $\mathrm{M}=28.85, \mathrm{SD}=4.65, t(147)=0.54, P>0.05)$ and had similar psychological symptomatology as measured by the Global Severity Index subscale of the SCL-90R (Treatment group: $\mathrm{M}=0.57, \mathrm{SD}=0.50$; Control group: $\mathrm{M}=0.51, \mathrm{SD}=0.39$, $t(147)=0.81, P>.05)$.

\section{Efficacy of treatment}

Means and standard deviations for the treatment and control groups for each dependent variable can be seen in Table 1.

A series of split plot analyses of variance (SPANOVA) were conducted to test for the efficacy of the treatment. All analyses involved the two between subject variables, Condition (Treatment/Control) and Medical Intervention (High/Low), and most incorporated the within subject variable of Time. The levels of the last variable differed across analyses depending on the occasions at which the dependent variables were 
Table 1. Descriptive statistics for the dependent variables over time.

\begin{tabular}{|c|c|c|c|c|c|c|c|c|c|}
\hline & \multirow[b]{3}{*}{ Time $^{c}$} & \multicolumn{4}{|c|}{ Treatment group } & \multicolumn{4}{|c|}{ Control group } \\
\hline & & \multicolumn{2}{|c|}{ Low $^{a}$} & \multicolumn{2}{|c|}{$\operatorname{High}^{\mathrm{b}}$} & \multicolumn{2}{|c|}{ Low $^{a}$} & \multicolumn{2}{|c|}{ High $^{\mathrm{b}}$} \\
\hline & & M & $(\mathrm{SD})$ & M & $(\mathrm{SD})$ & M & $(\mathrm{SD})$ & M & $(\mathrm{SD})$ \\
\hline \multicolumn{10}{|l|}{ EPDS } \\
\hline & 1 & 7.48 & $(5.78)$ & 7.35 & $(4.38)$ & 7.41 & $(5.49)$ & 6.33 & $(4.24)$ \\
\hline & 3 & 6.41 & $(6.10)$ & 6.45 & $(4.41)$ & 6.50 & $(5.32)$ & 6.97 & $(4.51)$ \\
\hline & 4 & 6.69 & $(5.27)$ & 6.13 & $(5.67)$ & 5.25 & $(4.98)$ & 5.57 & $(4.51)$ \\
\hline \multicolumn{10}{|l|}{ STAI } \\
\hline & 1 & 71.00 & $(25.23)$ & 68.64 & $(18.36)$ & 66.13 & $(22.09)$ & 61.97 & (15.56) \\
\hline & 3 & 67.59 & $(24.10)$ & 65.77 & $(18.29)$ & 65.44 & $(21.91)$ & 65.00 & (15.34) \\
\hline & 4 & 66.55 & $(24.60)$ & 63.21 & $(20.12)$ & 59.50 & (18.63) & 60.10 & $(16.71)$ \\
\hline \multicolumn{10}{|l|}{ POBS } \\
\hline & 2 & 106.00 & $(13.69)$ & 92.97 & (15.18) & 100.25 & $(16.06)$ & 97.03 & (17.07) \\
\hline & 3 & 111.31 & $(15.54)$ & 93.03 & $(19.45)$ & 99.72 & $(18.30)$ & 98.60 & (18.85) \\
\hline & 4 & 109.86 & $(17.03)$ & 89.92 & $(22.70)$ & 96.19 & $(17.66)$ & 92.83 & (23.13) \\
\hline \multicolumn{10}{|l|}{ DAS } \\
\hline & 1 & 114.28 & $(18.00)$ & 119.81 & $(14.80)$ & 113.74 & $(15.64)$ & 121.14 & (13.69) \\
\hline & 4 & 113.06 & $(19.81)$ & 118.59 & $(14.92)$ & 111.71 & $(16.15)$ & 112.86 & $(20.26)$ \\
\hline \multicolumn{10}{|l|}{ IES } \\
\hline & 3 & 8.76 & $(10.67)$ & 11.90 & $(11.76)$ & 6.25 & $(7.87)$ & 9.80 & $(8.60)$ \\
\hline & 4 & 6.72 & $(8.55)$ & 9.20 & $(10.10)$ & 5.47 & $(8.58)$ & 6.53 & $(7.31)$ \\
\hline & \multicolumn{8}{|c|}{ PSI } & (19.54) \\
\hline
\end{tabular}

${ }^{a}$ Low level of medical intervention.

${ }^{\mathrm{b}}$ High level of medical intervention.

'Time Period: 1 prepartum; $2 \quad 1 / 2$ days postpartum; 31 month postpartum; 43 months postpartum.

administered (prepartum, 1/2 days, 1 month and 3 months postpartum). In the case of parental stress, Time was not included in the analysis as this was measured only once at 3 months postpartum. Results can be seen in Table 2 .

As is evident from Table 2, results generally failed to show a main effect for Condition (postnatal debriefing), nor was it involved in any interaction except with Medical Intervention, in the case of POBS (Perceived problems with birth), and to a limited extent with Time, in the case of DAS (Dyadic Satisfaction).

The interaction $(P=0.06)$ between Condition and Time in the measure of Dyadic Satisfaction emerged as debriefed mothers showed a small and insignificant loss of satisfaction with their partners from prepartum $(M=117.25)$ to 3 months postpartum $(M=116.02)$, while mothers who were not debriefed showed a significant loss of satisfaction over the same period (Prepartum: $M=117.49 ; 3$ months postpartum: $M=112.29$ ).

The interaction between Condition and Medical Intervention for the POBS can be seen in Figure 1.

A Tukey HSD post hoc analysis showed that women who had high levels of medical intervention and were debriefed $(M=91.90)$ had more negative perceptions of the birth compared with women who had low levels of intervention and were debriefed 
Table 2. Split plot ANOVA analyses of the effects of condition, medical intervention and time on EPDS, STAI, $D A S$, and IES.

\begin{tabular}{llllll}
\hline Measure & df & $F$ & Partial $\eta^{2}$ & $P$ \\
\hline
\end{tabular}

\section{EPDS}

Between subjects effects

Condition (Treatment/Control)

Medical Intervention

Condition $\times$ Medical Intervention
1, 127
1,127
1,127

Within subjects effects

Time $^{\mathrm{a}}$

Condition $\times$ Time $^{\mathrm{a}}$

Medical Intervention $\times$ Time $^{a}$

Condition $\times$ Med Int $\times$ Time $^{a}$

\section{STAI}

Between subjects effects

Condition (Treatment/Control)

Medical Intervention

Condition $\times$ Medical Intervention

Within subjects effects

Time $^{\mathrm{a}}$

Condition $\times$ Time $^{\mathrm{a}}$

Medical Intervention $\times$ Time $^{a}$

Condition $\times$ Med Int $\times$ Time $^{\mathrm{a}}$

\section{POBS}

Between subjects effects

Condition (Treatment/Control)

Medical Intervention

Condition $\times$ Medical Intervention

Within subjects effects

Time $^{\mathrm{b}}$

Condition $\times$ Time $^{\mathrm{b}}$

Medical Intervention $\times$ Time $^{b}$

Condition $\times$ Med Int $\times$ Time $^{b}$

\section{DAS}

Between subjects effects

Condition (Treatment/Control)

Medical Intervention

Condition $\times$ Medical Intervention

Within subjects effects

Time $^{c}$

Condition $\times$ Time $^{c}$

Medical Intervention $\times$ Time $^{c}$

Condition $\times$ Med Int $\times$ Time $^{c}$

\section{IES}

Between subjects effects

Condition (Treatment/Control)

Medical Intervention

Condition $\times$ Medical Intervention
$1.85,234.47$

$1.85,234.47$

$1.85,234.47$

$1.85,234.47$

1,126
1,126
1,126

$1.89,238.10$

$1.89,238.10$

$1.89,238.10$

$1.89,238.10$

1,126
1,126
1,126

$1.67,210.52$

$1.67,210.52$

$1.67,210.52$

$1.67,210.52$

1,134

1,134

1,134

1,134

1,134

1,134

1, 134

1, 127

1, 127

1, 127
0.29

0.04

0.01

5.24

1.49

0.63

0.77

1.73

0.38

0.04

5.13

1.18

0.30

0.45

1.07

10.92

5.96

5.40

2.31

1.40

1.88

0.35

3.42

0.06

9.18

3.51

2.21

2.21

2.25
3.24
0.03

0.02

0.14

0.03

0.00

0.07

0.86
0.59

0.84

0.94

0.01

0.23

0.52

0.46

0.19

0.54

0.85

0.01

0.31

0.73

0.62

0.30

0.00

0.02

0.01

0.11

0.25

0.16

0.55

0.07

0.81

0.00

0.06

0.14

0.14 
Table 2. Continued.

\begin{tabular}{|c|c|c|c|c|}
\hline Measure & $\mathrm{df}$ & $F$ & Partial $\eta^{2}$ & $P$ \\
\hline \multicolumn{5}{|l|}{ Within subjects effects } \\
\hline Time $^{\mathrm{d}}$ & 1,127 & 6.62 & 0.05 & 0.01 \\
\hline Condition $\times$ Time $^{\mathrm{d}}$ & 1,127 & 0.04 & 0.00 & 0.84 \\
\hline Medical Intervention $\times$ Time $^{\mathrm{d}}$ & 1,127 & 0.85 & 0.01 & 0.36 \\
\hline Condition $\times$ Med Int $\times$ Time $^{d}$ & 1,127 & 0.28 & 0.00 & 0.60 \\
\hline \multicolumn{5}{|l|}{ PS1 } \\
\hline \multicolumn{5}{|l|}{ Between subjects effects } \\
\hline Condition (Treatment/Control) & 1,141 & 0.12 & 0.00 & 0.73 \\
\hline Medical Intervention & 1,141 & 1.80 & 0.01 & 0.18 \\
\hline Condition $\times$ Medical Intervention & 1,141 & 0.63 & 0.00 & 0.43 \\
\hline
\end{tabular}

Note: The Greenhouse Geisser adjustment correction was used for tests of within subjects effects.

Time $^{\mathrm{a}}$ Scores collected at three assessment points (prepartum, and 1 and 3 months postpartum).

Time $^{\mathrm{b}}$ Scores collected at three assessment points (1/2 days, and 1 and 3 months postpartum).

Time $^{\mathrm{c}}$ Scores collected at two assessment points (prepartum and 3 months postpartum).

Time $^{\mathrm{d}}$ Scores collected at two assessment points (1 and 3 months postpartum).

$(M=109.10)$. There was no difference between high $(M=96.20)$ and low $(M=98.7)$ intervention groups when no debriefing occurred.

There was a significant main effect of Medical Intervention for the POBS, and a strong suggestion of the effect for DAS and IES. Women who experienced more medical intervention during the birth of their child reported less positive perceptions of the birth, less satisfaction with their partners, and greater stress.

A statistical main effect of Time was evident on the EPDS, STAI, POBS, and IES, as indicated in Table 2. All participants reported significantly fewer symptoms of depression, and less anxiety, over time, from prepartum to 1 month postpartum and to 3 months postpartum. Participants also showed declining levels of stress from 1 to 3 months postpartum. Perceptions of the birth were not quite as consistent, being more positive at 1 month postpartum compared to 2 days postpartum, but were less positive at 3 months compared to 1 month postpartum.

\section{Women's feedback following debriefing}

FAD scores for both treatment and control groups at assessment point 4 (3 months postpartum, $n=111$ ), were not significantly different, indicating that all participants rated their postnatal debriefing in a similar fashion, whether it took place 2 days or 3

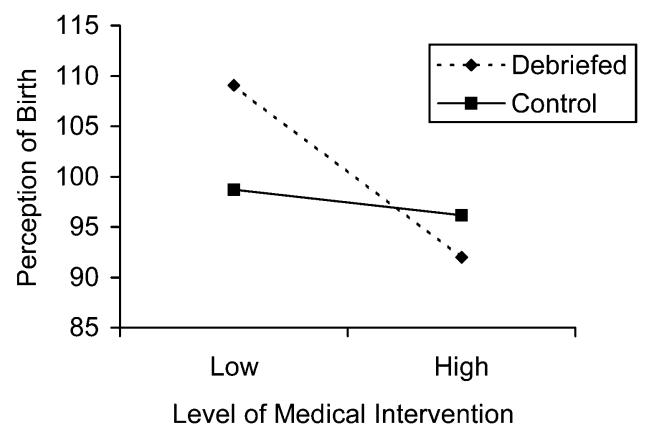

Figure 1. Mean POBS scores of treatment and control groups, split by degree of medical intervention in the birth. 
months after delivery $(t(109)=1.07, P=0.29)$. Over $90 \%$ of all participants rated their debriefing positively and indicated that debriefing was not threatening $(97.5 \%)$, or intrusive $(91.5 \%)$ and that it was very $(21.0 \%)$, or extremely $(73.1 \%)$ important for all women to have the chance to be debriefed. Almost all women $(95.7 \%)$ indicated that they had received information that was moderately to extremely useful and over $80 \%$ of women felt willing to talk about their birthing, and were comfortable talking with the midwife.

\section{Discussion}

The results of this study found women who were debriefed were no less likely to develop symptoms of postnatal depression (using the EPDS) than women who did not receive debriefing. This finding confirms the results of previous Australian studies (Henderson et al., 1998; Priest et al., 2003; Small et al., 2000), which used the same measure. The tendency for debriefed women to report more depression than nondebriefed women, noted by Small et al. (2000), was not evident in the current sample. EPDS scores decreased steadily over time for all participants.

Postnatal depression is an individual response, with multiple possible contributing factors from biological (Harris, 1994), psychological (McMahon et al., 2001) and psychosocial characteristics (Webster et al., 1994) according to the biopsychosocial model. The role of postnatal debriefing in the prevention of postnatal depression is to minimise the effect of exacerbating factors, relevant to the birth experience, which may influence the development of depressive symptoms. However other contributing factors still exist within the context of the woman's life, and a woman may be at risk of postnatal depression due to a variety of factors unrelated to the birth experience which postnatal debriefing does not and cannot address. Boyce and Condon (2001), in their criticism of the Small et al. (2000) study, in fact question whether a single session of debriefing could have an impact on postnatal depression, when other psychosocial variables contribute perhaps more significantly to its onset. It is to be noted, however, that this study measured EPDS responses at 1 and 3 months postpartum, whereas the two previous studies measured EPDS responses at 6 months. Postnatal depression may develop up to 6 months postpartum so the current study does not allow for women who may have developed postnatal depression between 3 and 6 months postpartum.

No differences were evident between women in the control and treatment groups on levels of anxiety, as the state anxiety level of all participants decreased over time regardless of treatment condition. Given that Green (1998) has shown that state STAI scores correlate strongly with EPDS scores at both prepartum and postpartum and that there were no significant differences on postnatal depression, this result is consistent with previous findings.

Interestingly there were some differences between women in the treatment and control groups on their levels of dyadic satisfaction (as measured by the DAS) over time. While debriefed mothers showed no loss of dyadic satisfaction from pre- to postpartum, mothers in the control condition did. As dyadic satisfaction is a strong predictor of postnatal depression (Webster et al., 1994), the impact of debriefing on dyadic satisfaction but its failure to effect postnatal depression is puzzling.

A partial answer to the puzzle may be evident in the effect of debriefing on perceptions of birth. High levels of medical intervention were found, not surprisingly, to adversely affect perceptions of birth. This finding is consistent with that of Cranley et al. (1983), who found less positive perceptions of birth among women who were delivered by 
caesarean. However, there was an additional and unexpected finding in relation to perceptions of the birth. Results indicated that women who experienced high levels of medical intervention during the birth of their children and who were debriefed had more negative perceptions of the birth compared to women who had low levels of medical intervention and who were debriefed. Such results raise the possibility that postnatal debriefing may be harmful for women who experience a difficult birth. This would be consistent with Small et al. 's (2000) suggestion of a negative effect of postnatal debriefing on traumatised women, though the Small et al. study focused on women with operative delivery only. Given that the present study included all births, the capacity for debriefing to actually exacerbate negative perceptions among mothers who experience high levels of intervention might account for the small and limited effect of debriefing more generally. Thus, only on the measure of dyadic satisfaction, a measure not directly concerned with the birthing experience, did debriefing show signs of arresting the decline in satisfaction with partner that typically coincides with the birth of a child.

Levels of parental stress (as measured by the PSI) did not differ at 1 and 3 months postpartum between women in the treatment and control groups. Milgrom and McCloud (1996) have shown that women with postnatal depression rate their infant, and their relationship with their infant, more negatively than controls. Debriefed women in this study did not rate their infant or their relationship with their infant differently from women in the control group.

Finally, it should be noted that all participants' level of trauma generally decreased over time, regardless of condition. This is consistent with previous writings (e.g. Stuhlmiller \& Dunning, 2000; Turton et al., 2001) concerning the high spontaneous reduction in symptoms over time among trauma survivors who receive no treatment.

Despite the lack of clear statistical evidence supporting the benefits of postnatal debriefing, women who were debriefed rated the experience positively. This is consistent with previous research (Henderson et al., 1998; Small et al., 2000) and anecdotal evidence. Allen (1999), for example, in a study of 61 women, reported that a number of participants with a high score on the EPDS or the IES spoke of the benefit of talking to, or the need to talk to others, including health professionals, about their experience. Women perceive the discussion of their birthing, and the sharing of information that takes place, to be helpful and report positively on the experience. The majority of women on the maternity ward of the participating hospital accepted the opportunity of debriefing when it was offered. Women who have been debriefed after a previous birthing asked when their debriefing for the current birthing would take place.

In summary, this study has confirmed the results of previous studies which recognised that women appreciate the opportunity to talk and gain information about their birthing. The study has also provided support for previous research that concluded that postnatal debriefing does not significantly affect psychological variables related to depression, anxiety or trauma symptoms following childbirth. However, it is has provided some indication that debriefing may arrest declines in dyadic satisfaction.

Several years ago Alexander (1998) highlighted the lack of clarity of terminology with respect to postnatal debriefing, along with the lack of its systematic evaluation. It seems evident that women appreciate the opportunity to review their birth experience and clarify events with a midwife (Bondas-Salonen, 1998; Charles \& Curtis, 1994; Henderson et al., 1998; Small et al., 2000). Whether this review should comprise 'psychological debriefing' or some other form of self-reflection requires further examination. It may be that a birthing review, as an opportunity for women to gain 
information about their birthing, constitutes appropriate quality of care in its own right for those women who experience less medical intervention, regardless of measurable psychological benefits. However, for those women who experience more medical intervention other protocols may need to be developed and implemented.

This study is limited by statistical, methodological, and extraneous or confounding variable considerations. First, statistically, the number of measures used ideally requires a larger population to sustain the number of analyses performed at the 0.05 level of significance. Second, only self-report measures were used; there was no clinical assessment of depression, anxiety or birth trauma. However, given that the measures used (EPDS, STAI, SCL-90R, IES, and POBS) have been consistently reported in the literature as having good psychometric properties and have been widely used in previous research, combined with the broad investigative nature of the study, it was reasoned that their use was appropriate. Finally, the study may have been inadvertently affected by confounding or extraneous variables, such as different delivery staff, and factors relating to the debriefing midwife (the midwife in this study was also responsible for parenting craft in the hospital).

As Raphael and Wilson (2000) point out, the use of the term debriefing has powerful connotations which presume an activity with a formalised structure which has been derived from a militaristic model of intervention. The widespread use of the term 'debriefing' to cover all potential psychological interventions in association with life experience must be a cause for concern, as is any suggestion of widespread use of this type of intervention for what is, in the majority of instances, a normal and joyful experience. The recovery from childbirth should be facilitated and not pathologised. 'Normal' recovery from this experience may include the forgetting of trauma and the spontaneous remission of trauma symptoms over time, perhaps providing understanding relevant to normal recovery from other major life experiences.

Recommending debriefing for all women presupposes that childbirth is traumatic for all women, rather than potentially traumatic for some women. The term birth review is preferable both semantically and practically as it carries with it no dramatic connotation. The results of this study indicate that while having the opportunity to discuss their birthing experience is regarded positively by women, and that debriefing may have some limited impact on dyadic satisfaction, there is little empirical support for its routine use to reduce postnatal depression, anxiety, trauma or parenting stress. Indeed, there is some evidence to suggest that such a procedure may be harmful for women who experience a difficult birth.

\section{References}

AbIdin, R. (1995). Parenting Stress Index Professional Manual. Charlottesville, VA: Psychological Assessment Resources.

Albright, A. (1993). Postpartum depression: An overview. Fournal of Counseling E Development, 71, 31619. Alexander, J. (1998). Confusing debriefing and defusing postnatally: The need for clarity of terms, purpose and value. Midwifery, 14, 122124 .

Allen, H. (1999). 'How was it for you?' Debriefing for postnatal women: Does it help? Professional Care of Mother and Child, 9, 7779.

Astbury, J., Brown, S., Lumley, J. \& Small, R. (1994). Birth events, birth experiences and social differences in postnatal depression. Australian fournal of Public Health, 18, 176184.

BALL, J. (1988). Mothers need nurturing, too. Nursing Times, 84, 2931.

Bergant, A., Heim, K., Ulmer, H. \& Illmensee, K. (1999). Early postnatal depressive mood: Associations with obstetric and psychosocial factors. Fournal of Psychosomatic Research, 46, 391394. 
Bondas SAlonen, T. (1998). New mothers experiences of post partum care a phenomenological follow up study. Fournal of Clinical Nursing, 7, 165174.

Boyce, P. \& Condon, J. (2000). Traumatic childbirth and the role of debriefing. In: B. Raphael \& J.P. Wilson (Eds), Psychological debriefing: Theory, practice and evidence (pp. 272 280). New York: Cambridge University Press.

Boyce, P., Stubbs, J. \& Todd, A. (1993). The Edinburgh Postnatal Depression Scale: Validation for an Australian sample. Australian and New Zealand fournal of Psychiatry, 27, 472476.

Burger, J., Mccue Horwitz, S., Forsyth, B., Leventhal, J.M. \& Leaf, P.J. (1993). Psychological sequelae of medical complications during pregnancy. Pediatrics, 91, 566571.

Charles, J. \& Curtis, L. (1994). Birth afterthoughts: A listening and information service. British fournal of Midwifery, 2, 331334.

Clement, S., Wilson, J. \& Sikorski, J. (1999). The development of an intrapartum intervention score based on women's experiences. Fournal of Reproductive and Infant Psychology, 17, 5362.

Cox, J. (1986). Postnatal depression: A guide for health professionals. New York: Churchill Livingstone.

Cox, J., Chapman, G., Murray, D. \& Jones, P. (1996). Validation of the Edinburgh Postnatal Depression Scale in non postnatal women. Fournal of Affective Disorders, 39, 185189.

Cranley, M., Hedahl, K. \& PegG, S. (1983). Women's perceptions of vaginal and cesarean deliveries. Nursing Research, 32, 1015.

Crompton, J. (1996). Post traumatic stress disorder and childbirth. British fournal of Midwifery, 4, 290294.

Da Costa, D., Larouche, J., Dritsa, M. \& Brender, W. (2000). Psychosocial correlates of prepartum and postpartum depressed mood. Fournal of Affective Disorders, 59, 3140.

Derogatis, L.R. (1994). SCL 90 R Symptom Checklist 90 R: Administration, Scoring and Procedures manual. Minneapolis, MN: National Computer Systems.

Fawcett, J. \& KNAUth, D. (1996). The factor structure of the perception of birth scale. Nursing Research, 45, 8386.

Fawcett, J., Pollio, N. \& Tully, A. (1992). Women's perceptions of cesarean and vaginal delivery: Another look. Research in Nursing and Health, 15, 439446.

Fisher, J., Astbury, J. \& SMiTh, A. (1997). Adverse psychological impact of operative obstetric interventions: A prospective longitudinal study. Australian and New Zealand fournal of Psychiatry, 31, 728738 .

Gotlib, I., Whiffen, V., Wallace, P. \& Mount, J. (1991). Prospective investigation of postpartum depression: factors involved in onset and recovery. Fournal of Abnormal Psychology, 100, 122132.

GREEN, J.M. (1993). Expectations and experiences of pain in labour: Findings from a large prospective study. Birth: Issues in Perinatal Care and Education, 20, 6572.

GreEn, J. (1998). Postnatal depression or perinatal dysphoria? Findings from a longitudinal community based using the Edinburgh Postnatal Depression Scale. Fournal of Reproductive and Infant Psychology, 16, 143155.

HARRIS, B. (1994). Biological and hormonal aspects of postpartum depressed mood. British fournal of Psychiatry, 164, 288292.

Henderson, J., Sharp, J., Priest, S., Hagan, R. \& Evans, S. (1998, March April). Postnatal debriefing: What do women feel about it? Paper presented at the Perinatal Society of Australia and New Zealand Conference, Alice Springs, Australia.

Horowitz, M., Wilner, N. \& Alvarez, W. (1979). Impact of Event Scale: A measure of subjective stress. Psychosomatic Medicine, 41, 209218.

LAVENDER, T. \& Walkinshaw, S. (1998). Can midwives reduce postpartum psychological morbidity? A randomised trial. Birth: Issues in Perinatal Care and Education, 25, 215219.

Kaplan, Z., IANCU, I. \& Bodner, E. (2001). A review of psychological debriefing after extreme stress, Psychiatric Services, 52, 824827.

LeE, C., Slade, P. \& Lygo, V. (1996). The influence of psychological debriefing on emotional adaption in women following early miscarriage: A preliminary study. British fournal of Medical Psychology, 69, 4558.

LyONS, S. (1998). A prospective study of post traumatic stress symptoms 1 month following childbirth in a groups of 42 first time mothers. Fournal of Reproductive and Infant Psychology, 16, 91105.

MADSEN, L. (1994). Rebounding from childbirth: Toward emotional recovery. Westport, VA: Bergin and Garvey.

MARUT, J.S. \& MERCER, R.T. (1979). Comparisons of primiparas' perceptions of vaginal and cesarean births. Nursing Research, 28, 260266.

McMahon, C., Barnett, B., Kowalenko, N., Tennant, C. \& Don, N. (2001). Postnatal depression, anxiety and unsettled infant behaviour. Australian and New Zealand fournal of Psychiatry, 35, 581588. 
MERCER, R.T. \& FERKeTICH, S.L. (1990). Predictors of parental attachment during early parenthood. fournal of Advanced Nursing, 15, 268280.

Milgrom, J. \& McCloud, P. (1996). Parenting stress and postnatal depression. Stress Medicine, 12, 177186.

Murray, L. \& Carothers, A. (1990). The validation of the Edinburgh Postnatal Depression Scale on a community sample. British fournal of Psychiatry, 157, 288290.

Priest, S.R., Henderson, J., Evans, S.F. \& Hagan, R. (2003). Stress debriefing after childbirth: A randomised controlled trial. Medical fournal of Australia, 178, 542454.

RAPHAEL, B., \& SPRAgue, T. (1996). Mental health and prevention for families. Family Matters, 44, 2629.

Raphael, B., \& Wilson, J.P. (Eds) (2000). Psychological debriefing: Theory, practice and evidence. Cambridge, UK: Cambridge Press.

Raphael Leff, J. (1991). Psychological Processes of Childbearing. London: Chapman \& Hall.

Rhodes, N. \& Hutchinson, S. (1994). Labour experiences of childhood sexual abuse survivors. Birth: Issues in Perinatal Care and Education, 21, 21320.

Rose, S. (1997). Psychological debriefing: History and methods. Counselling, 8, 4851.

Simkin, P. (1991). Just another day in a women's life? Women's long term perceptions of their first birth experience. Birth: Issues in Perinatal Care and Education, 18, 203210.

Small, R., Lumley, J., Donohue, L., Potter, A. \& Waldenstrom, U. (2000). Randomised controlled trial of midwife led debriefing to reduce maternal depression after operative childbirth. British Medical fournal, 321, 10431047.

Smith, J. \& Mitchell, S. (1996). Debriefing after childbirth: A tool for effective risk management. British fournal of Midwifery, 4, 58186.

SNaith, R.P. \& Zigmond, A.S. (1994). The Hospital and Anxiety Depression Scale Manual. Windsor: NFER Nelson.

SPANIER, G. (1989). Manual for the Dyadic Adjustment Scale. North Tonawanda, NY: Multi Health Systems.

SpIElberger, C.D. (1983). State Trait Anxiety Inventory for Adults. Redwood City, CA: Mind Garden.

Stuhlmiller, C. \& DunNing, C. (2000). Concerns about debriefing: Challenging the mainstream. In: B. Raphael \& J.P. Wilson (Eds), Psychological debriefing: Theory, practice and evidence (pp. 305 317). New York: Cambridge University Press.

Turner, S. \& LEE, D. (1998). Measures in post traumatic stress disorder. A practitioner's guide. Berkshire, UK: Nfer Nelson.

Turton, P., Hughes, P., Evans, C. \& Fainman, D. (2001). Incidence, correlates and predictors of post traumatic stress disorder in the pregnancy after childbirth. British fournal of Psychiatry, 178, 556560.

Vines, S.W. \& Williams BuRgess, C. (1994). Effects of a community health nursing parent baby (Ad)venture program on depression and other selected maternal child health outcomes. Public Health Nursing, 11, 188195.

Webster, M.L., Thompson, J., Mitchell, E.A. \& Werry, J.S. (1994). Postnatal depression in community cohort. Australian and New Zealand fournal of Psychiatry, 28, 4249.

Westley, W. (1997). 'Time to talk'. Listening Service. Midwives, 110, 3031. 